University of Minnesota Morris Digital Well

University of Minnesota Morris Digital Well

8-21-2019

\title{
Synthesis of Unsymmetrical Bis(phosphine) Oxides and Their Phosphines via Secondary Phosphine Oxide Precursors
}

James R. Pedroarena

University of Oregon

Bryan P. Nell

University of Minnesota - Morris, bnell@morris.umn.edu

Lev N. Zakharov

University of Oregon

David R. Tyler

University of Oregon

Follow this and additional works at: https://digitalcommons.morris.umn.edu/chem_facpubs

Part of the Polymer Chemistry Commons

\section{Recommended Citation}

Pedroarena, J.R.; Nell, B. P.; Zakharov, L. N.; Tyler, D. R. J. Synthesis of Unsymmetrical Bis(phosphine) Oxides and Their Phosphines via Secondary Phosphine Oxide Precursors. Inorg. Organomet. Polym. (2019)

This Article is brought to you for free and open access by the Faculty and Staff Scholarship at University of Minnesota Morris Digital Well. It has been accepted for inclusion in Chemistry Publications by an authorized administrator of University of Minnesota Morris Digital Well. For more information, please contact skulann@morris.umn.edu. 


\section{Synthesis of Unsymmetrical Bis(phosphine) Oxides and their Phosphines via Secondary Phosphine Oxide Precursors}

James R. Pedroarena, Bryan P. Nell, Lev N. Zakharov, and David. R. Tyler*

Department of Chemistry and Biochemistry, 1253 University of Oregon, Eugene, OR, 97403, United States

Suggested running head: Unsymmetrical Bis(phosphine) Oxides and Phosphines

Contact Information:

Professor David Tyler

Department of Chemistry and Biochemistry

1253 University of Oregon

Eugene, OR, USA 97403

dtyler@uoregon.edu

Phone: +1-541-346-4649; Fax: +1-541-346-0487

\section{SUMMARY}

The unsymmetrical bidentate phosphine ligands $(\mathrm{Me})_{2} \mathrm{PCH}_{2} \mathrm{CH}_{2} \mathrm{CH}_{2} \mathrm{P}(\mathrm{Et})_{2}(\mathbf{1 4})$, (Me $)_{2} \mathrm{PCH}_{2} \mathrm{CH}_{2} \mathrm{CH}_{2} \mathrm{P}(\mathrm{iPr})_{2}(\mathbf{1 5}),(\mathrm{Me})_{2} \mathrm{PCH}_{2} \mathrm{CH}_{2} \mathrm{CH}_{2} \mathrm{P}(\mathrm{Cy})_{2}$ (16), and $(\mathrm{Me})_{2} \mathrm{PCH}_{2} \mathrm{CH}_{2} \mathrm{CH}_{2} \mathrm{P}(\mathrm{Ph})_{2}$

(17) were synthesized using air-stable phosphine oxide intermediates. In the first step, sodium phosphinites formed by deprotonation of $(\mathrm{Me})_{2} \mathrm{P}(\mathrm{O}) \mathrm{H},(\mathrm{Et})_{2} \mathrm{P}(\mathrm{O}) \mathrm{H}$, and $(\mathrm{iPr})_{2} \mathrm{P}(\mathrm{O}) \mathrm{H}$ were alkylated by 1-bromo-3-chloropropane. The different substitution rates of the chloride and bromide groups allowed the isolation of the intermediates $(\mathrm{Me})_{2} \mathrm{P}(\mathrm{O}) \mathrm{CH}_{2} \mathrm{CH}_{2} \mathrm{CH}_{2} \mathrm{Cl}$ (2), (Et) $)_{2} \mathrm{P}(\mathrm{O}) \mathrm{CH}_{2} \mathrm{CH}_{2} \mathrm{CH}_{2} \mathrm{Cl}(3)$, and (iPr) ${ }_{2} \mathrm{P}(\mathrm{O}) \mathrm{CH}_{2} \mathrm{CH}_{2} \mathrm{CH}_{2} \mathrm{Cl}$ (4). Subsequent reaction of $(\mathrm{Me})_{2} \mathrm{P}(\mathrm{O}) \mathrm{CH}_{2} \mathrm{CH}_{2} \mathrm{CH}_{2} \mathrm{Cl}$ (2) with the sodium phosphinites generated from $(\mathrm{Et})_{2} \mathrm{P}(\mathrm{O}) \mathrm{H}$, $(\mathrm{iPr})_{2} \mathrm{P}(\mathrm{O}) \mathrm{H},\left({ }^{\mathrm{t}} \mathrm{Bu}\right)_{2} \mathrm{P}(\mathrm{O}) \mathrm{H},(\mathrm{Cy})_{2} \mathrm{P}(\mathrm{O}) \mathrm{H}$, or $(\mathrm{Ph})_{2} \mathrm{P}(\mathrm{O}) \mathrm{H}$ gave unsymmetrical bidentate phosphine oxides; reduction of these oxides yielded the unsymmetrical phosphines. The unsymmetrical 
bidentate phosphines react with metal salts to form complexes. X-ray crystal structures of cis$\mathrm{Pt}\left((\mathrm{Me})_{2} \mathrm{P}\left(\mathrm{CH}_{2} \mathrm{CH}_{2} \mathrm{CH}_{2}\right) \mathrm{P}(\mathrm{Pr})_{2}\right) \mathrm{Cl}_{2}$ (20) and racemic $\left[\mathrm{Cu}^{\mathrm{I}}\left((\mathrm{Me})_{2} \mathrm{P}\left(\mathrm{CH}_{2} \mathrm{CH}_{2} \mathrm{CH}_{2}\right) \mathrm{P}(\mathrm{Ph})_{2}\right)\right] \mathrm{Cl}$ (21) were obtained. The kinetics and scope of the synthetic route were also explored. Experiments showed that the rate of substitution of the alkyl chloride group in $(\mathrm{R})_{2} \mathrm{P}(\mathrm{O}) \mathrm{CH}_{2} \mathrm{CH}_{2} \mathrm{CH}_{2} \mathrm{Cl}$-type oxides increases relative to unsubstituted alkyl chlorides due to the presence of the phosphonyl group on one end of the molecule. The scope of the reaction involving 1,2-dihaloalkanes was also investigated, and it was found that the reaction mixture of sodium dimethylphosphinite and 1,2-dihaloalkanes formed tetramethylbis(phosphine) monoxide (22), which decomposes on work-up to give complex reaction mixtures.

KEY WORDS: unsymmetrical phosphines; unsymmetrical phosphine oxides; phosphine ligands; phosphinite anions; heteroleptic phosphines

\section{Introduction}

Bidentate ligands have found extensive use in transition metal catalysis, including use in the preparation of polymer materials [1-4].

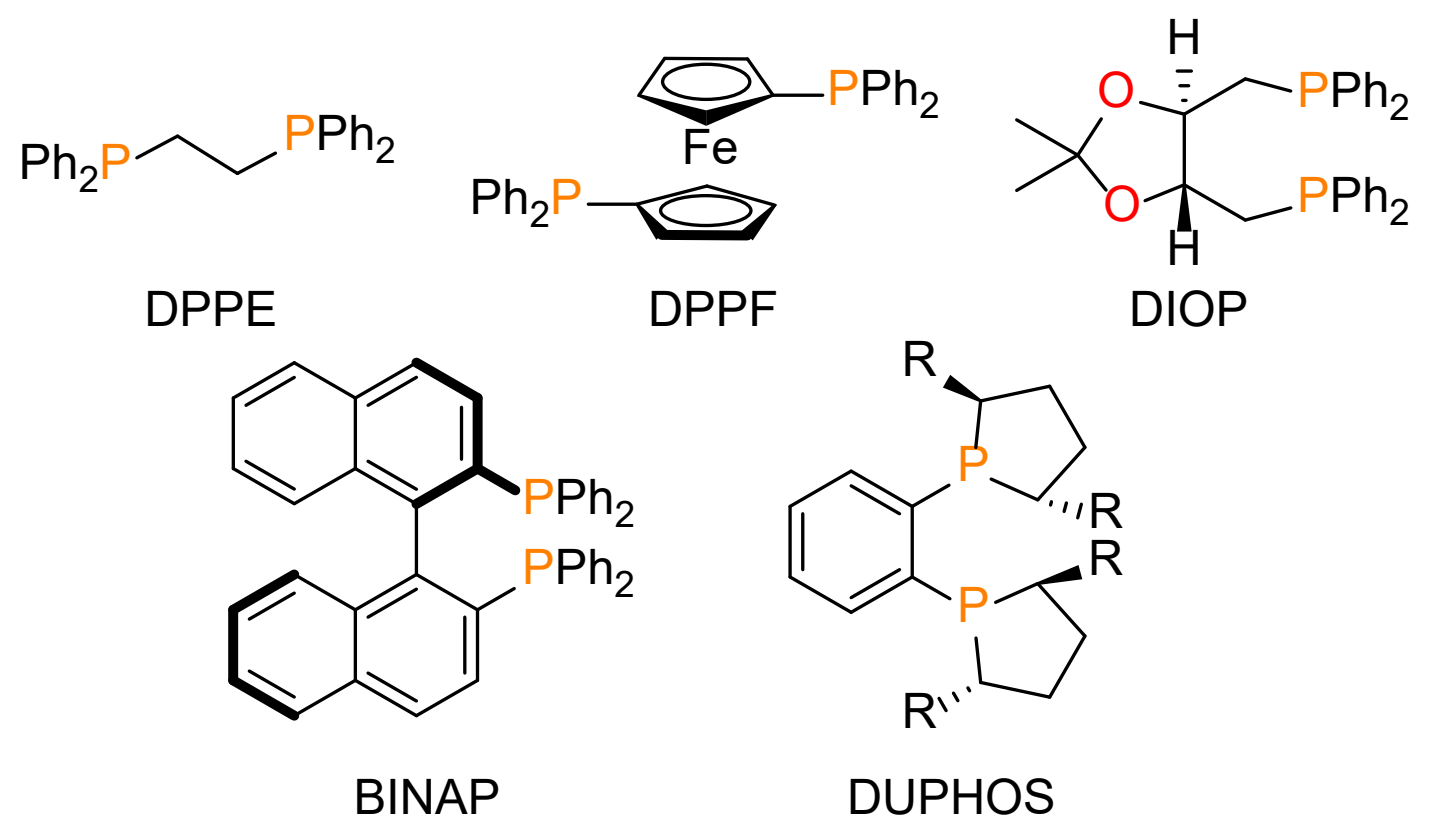


Figure 1. Examples of symmetric and $\mathrm{C}_{2}$-symmetric phosphine ligands

Bidentate ligands can either be symmetric or unsymmetric. For example, the bidentate ligands in Figure 1 are symmetric (DPPE [5] and DPPF [6]) or " $\mathrm{C}_{2}$-symmetric" (DIOP [7], BINAP [8], and DUPHOS [9]). The donor atoms on symmetric and $\mathrm{C}_{2}$-symmetric bidentate phosphine ligands all possess the same carbon groups, which means that the electronic and steric properties at each phosphorus center are the same [10]. In contrast, bidentate ligands can have different groups bonded to the donor atoms, making them unsymmetrical. Many examples of unsymmetrical ligands exist, notably: salen ligands ( $\mathrm{N}$ donor atoms) [11], bypyridine and other bidentate pyridine ligands $[12,13]$, phosphine-carboxylate ligands [3], phosphine-carboxylate ligands [1], phosphine-phosphine oxide ligands [14], phosphine-phosphite ligands [15], phosphinephosphinite ligands [15], and NHC ligands [16]. However, it is uncommon to encounter unsymmetrical phosphine-phosphine ligands [17-25]. Unsymmetrical phosphines are rare due to their lengthy syntheses as a result of the necessary stepwise addition of the $-\mathrm{PR}_{2}$ groups to the backbone and the use of pyrophoric secondary phosphines and chlorophosphines [17-25]. Such ligands may have use in tuning catalysts by providing two electronically and sterically different donor phosphorus atoms [25]. Unsymmetrical ligands can potentially convey intermediate properties to metal centers compared to symmetric ligands, and thus easier syntheses of them would allow for exploration of their ability to tune catalysts.

There are several applications of unsymmetrical ligands. For example, nickel and palladium catalysts with phosphine-imine ligands for ethylene polymerization have been shown to perform as well as and have higher temperature stability than analogous catalysts with imineimine ligands [3]. Furthermore, the activity of the palladium-catalyzed asymmetric 
copolymerization of propene and carbon monoxide benefits from the use of an unsymmetrical chiral phosphine-phosphite ligand [2]. Additionally, the use of unsymmetrical phosphinephosphite [26], phosphine-phosphinite [26], phosphine-imine [27], phosphinite-imine [27], and phosphine-phosphine [25] bidentate ligands in asymmetric catalytic processes can increase stereoselectivity. Finally, it is also noted that bidentate phosphine ligands are capable of forming coordination polymers with interesting properties [28-30]. Unsymmetrical bidentate phosphines are potentially useful in tweaking the properties of these materials.

The development of synthetic routes to tertiary phosphines via air-stable intermediates and easier workups has been of great interest to our research group [31,32]. In this work, we demonstrate the synthesis of unsymmetric bidentate phosphines utilizing air-stable phosphine oxide starting materials and intermediates. The synthetic route [32] employs nucleophilic phosphinite anions, generated by deprotonation of secondary phosphine oxides (SPOs) with sodium hexamethyldisilazide (NaHMDS), followed by the alkylation of the anions with alkyl halides to form tertiary phosphine oxides, Scheme 1 [32].

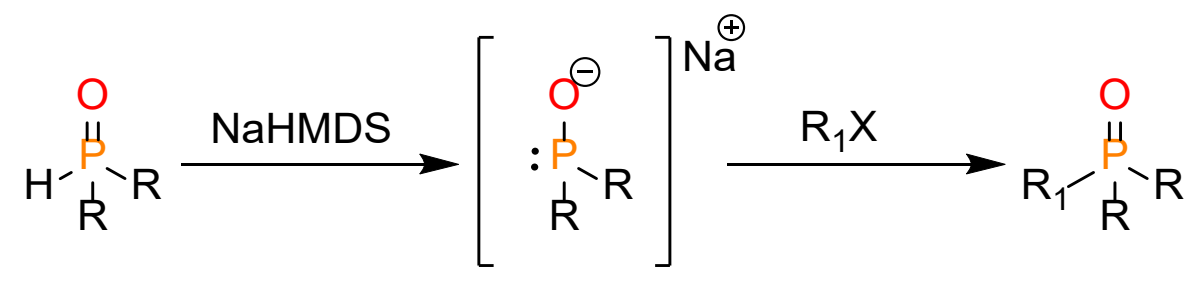

Scheme 1. Deprotonation and subsequent alkylation of SPOs using NaHMDS

In prior work [32], we showed that the phosphinite anions displayed reactivity suggestive of an $\mathrm{S}_{\mathrm{N}} 2$-like mechanism, as indicated by their sensitivity to steric constraints and by their reactivity with alkyl halides following the trend $\mathrm{RI}>\mathrm{RBr}>\mathrm{RCl}$. The observed regioselectivity 
allowed for isolation of $(\mathrm{Me})_{2} \mathrm{P}(\mathrm{O})\left(\mathrm{CH}_{2}\right)_{3-5} \mathrm{Cl}$ species and subsequent reaction to form unsymmetrical bis(phosphine) oxides $(\mathrm{Me})_{2} \mathrm{P}(\mathrm{O})\left(\mathrm{CH}_{2}\right)_{3-5} \mathrm{P}(\mathrm{O})(\mathrm{t}-\mathrm{Bu})_{2}$ [32], Scheme 2.
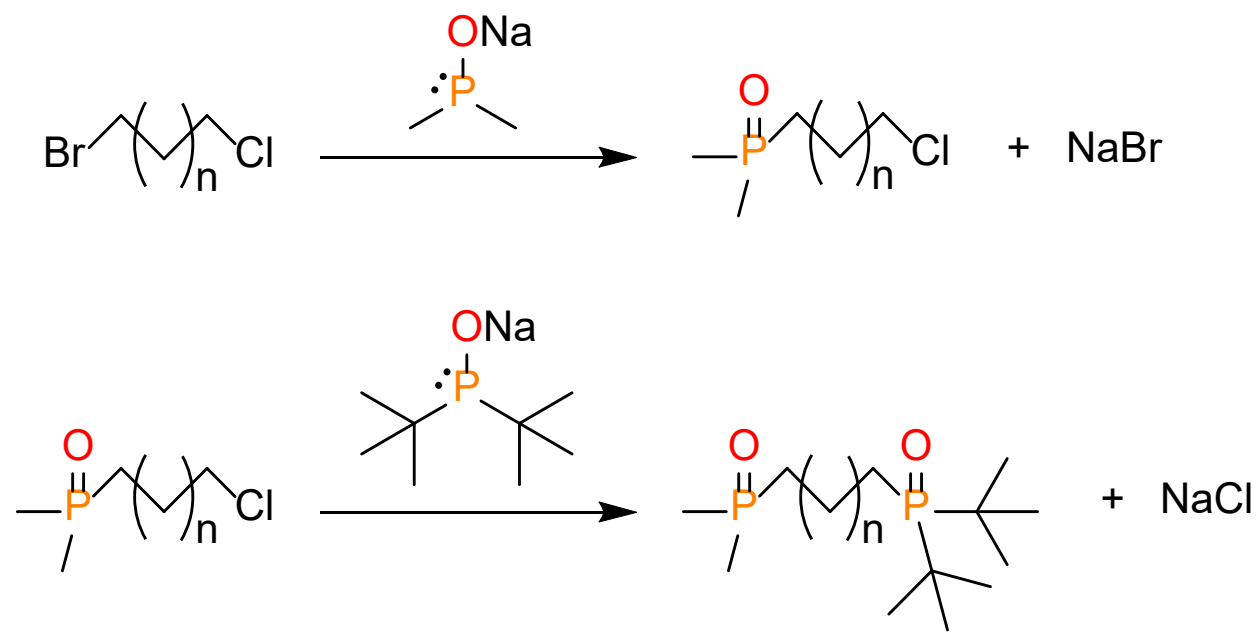

Scheme 2. Synthesis of unsymmetrical bis(phosphine) oxides[32], $n=1-3$

In this study, we extend our prior work to include the synthesis of $(\mathrm{R})_{2} \mathrm{P}(\mathrm{O}) \mathrm{CH}_{2} \mathrm{CH}_{2} \mathrm{CH}_{2} \mathrm{Cl},(\mathrm{Me})_{2} \mathrm{P}(\mathrm{O}) \mathrm{CH}_{2} \mathrm{CH}_{2} \mathrm{CH}_{2} \mathrm{P}(\mathrm{O})(\mathrm{R})_{2} /(\mathrm{Et})_{2} \mathrm{P}(\mathrm{O}) \mathrm{CH}_{2} \mathrm{CH}_{2} \mathrm{CH}_{2} \mathrm{P}(\mathrm{O})(\mathrm{Pr})_{2}$ (where $\mathrm{R}=\mathrm{Et}$, iPr, t-Bu, $\mathrm{Cy}, \mathrm{Ph}$ ), $(\mathrm{Me})_{2} \mathrm{PCH}_{2} \mathrm{CH}_{2} \mathrm{CH}_{2} \mathrm{P}(\mathrm{R})_{2}$, and several metal complexes with the unsymmetrical phosphine ligands. To our knowledge, this is the first report of unsymmetrical bidentate phosphine ligands synthesized using only air-stable starting materials and intermediates. In order to demonstrate the coordination chemistry of these ligands, two X-ray crystal structures of the metal complexes with unsymmetrical ligands were obtained. Additionally, the kinetics and the scope of the synthetic route were investigated.

\section{Results and Discussion}

\section{1 (3-chloropropyl)dialkylphosphine oxides, $(\mathrm{R})_{2} \mathrm{P}(\mathrm{O}) \mathrm{CH}_{2} \mathrm{CH}_{2} \mathrm{CH}_{2} \mathrm{Cl}$}


Synthesis of the (3-chloropropyl)dialkylphosphine oxide (precursors to the unsymmetrical bis(phosphine) oxides) was carried out following the reaction conditions shown in Scheme 3.

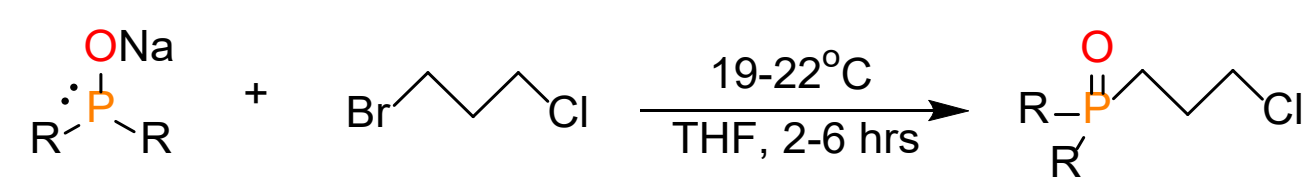

Scheme 3. Reaction of the phosphinite anion with 1-bromo-3-chloropropane

Very low yields of the mixed alkyl halide phosphine oxides products were obtained in our early study of the reactions of phosphinite anions with 1-bromo-3-chloropropane. The low yields for the reactions were attributed to loss of the product in the aqueous phase during the extraction process due to the water-solubility of the product. However, isolation of the disubstituted product $(\mathrm{Me})_{2} \mathrm{P}(\mathrm{O}) \mathrm{CH}_{2} \mathrm{CH}_{2} \mathrm{CH}_{2} \mathrm{P}(\mathrm{O})(\mathrm{Me})_{2}(\mathbf{1} ; 62 \%$ yield; Scheme 4) demonstrated that the low yields were the result of subsequent substitution at the alkyl chloride position after the initial substitution of the bromide. (Similar disubstituted products were also found in every other reaction of a phosphinite anion with 1-bromo-3-choropropane.) Substitution of the chloride is contrary to the observations in our previous study [32], which suggested little to no substitution would occur at the chloride position in the time it would take to substitute the bromide. The comparable rates of reaction observed in the current study may be due to the presence of the phosphonyl group near the alkyl chloride, which could stabilize the transition state by interacting with the $\mathrm{Na}^{+}$counterion (Figure 2A). Alternatively, the sodium counterion may associate closely with the oxygen atom of the phosphonyl group, leading to a preferred encounter between the phosphorus atom and the alkyl chloride (Figure 2B). 


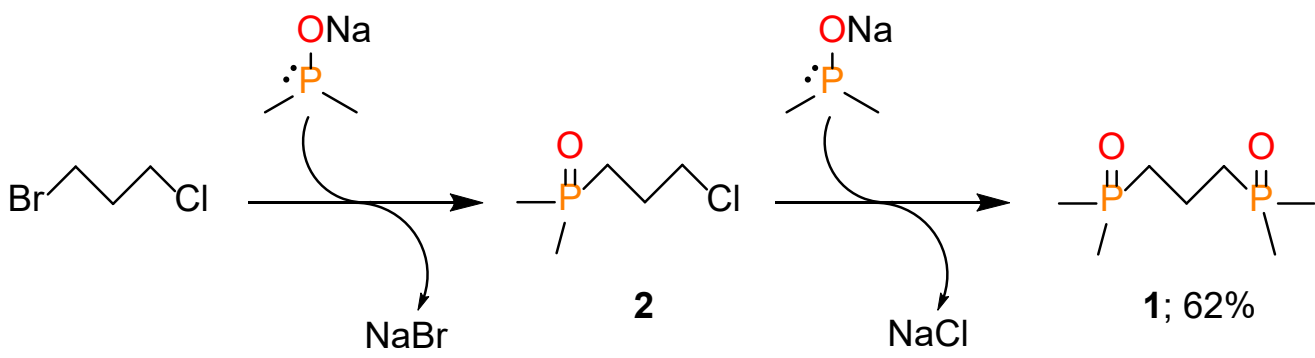

Scheme 4. Formation of the symmetrically substituted bidentate product leads to lower yields of the alkyl chloride phosphine oxides.

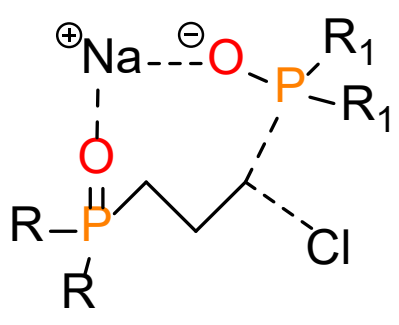

A
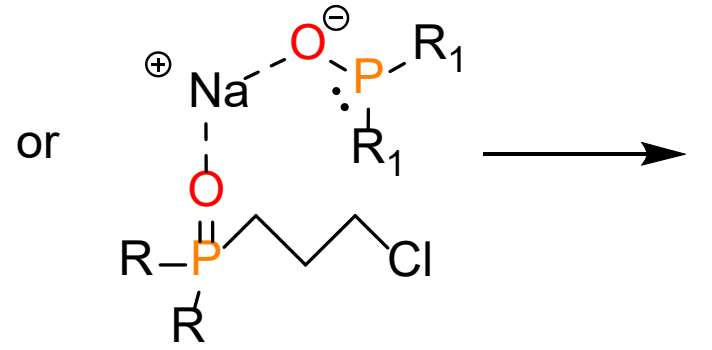<smiles>[R][R]([R])([R])CCCP([R7])([R])=O</smiles>

Figure 2. Hypothesized reasons for the increased rate of the substitution reaction of (3-

chloropropyl)dialkylphosphine oxides. a) In this hypothesis, interaction of the oxygen atom of the phosphonyl group with the $\mathrm{Na}^{+}$ion stabilizes the transition state. b) In this hypothesis, complexation of the sodium cation by phosphonyl increases the likelihood of the substitution reaction. 
In order to overcome the low yields, a slight excess of 1-bromo-3-chloro propane was used and the phosphinite anions were added slowly to the solution of 1-bromo-3-chloropropane. (Note that addition of the phosphinite anion to the reaction solution is opposite to the procedure in our previous work [32]. Addition of the phosphinite to the 1-bromo-3-chloro propane led to respectable increases in the yields, Table 1.)

Table 1. (3-chloropropyl)dialkylphosphine oxides

\begin{tabular}{ccc}
\hline 2 & Product & Yield (\%) \\
\hline 3 & & \\
4 & &
\end{tabular}

${ }^{a}$ Average of two isolated yields

In addition to the three oxides in Table 1, attempts were made to generate and isolate the di-tert-butyl- (5) and dicyclohexyl- (6) substituted (3-chloropropyl)dialkylphosphine oxides (Figure 3). However, these molecules could not be reliably separated at a sufficient purity from the impurities in the reaction mixtures. 


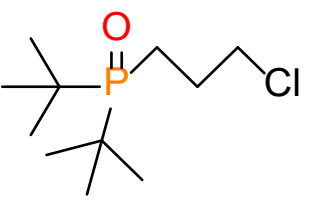

5

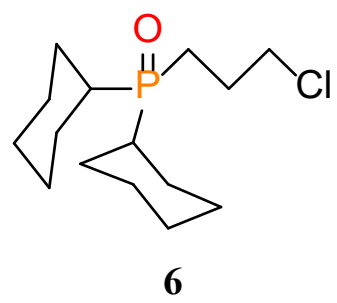

Figure 3. Product molecules 5 and $\mathbf{6}$ that could not be purified reliably. These molecules would require larger scale reactions in order to separate the impurities which are very similar in polarity, solubility, and boiling point.

It is of note that in almost every case, crude material obtained from the reaction of one of the phosphinite anions with 1-bromo-3-chloropropane contained a small amount of (3bromopropyl)dialkylphosphine oxide product (7; Figure 4). However, formation of 7 was not an issue because only a minor amount formed, and it was easily separated by distillation. A crystal structure of the (3-chloropropyl)dimethylphosphine oxide species (2) is shown in Figure 5.

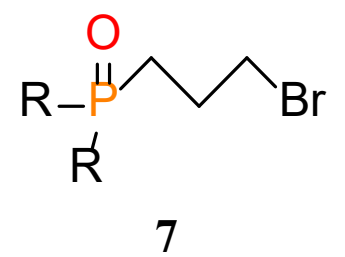

Figure 4. (3-Bromopropyl)dialkylphosphine oxide product (7), a minor product formed during the reaction of sodium phosphinites with 1-bromo-3-chloropropane. 


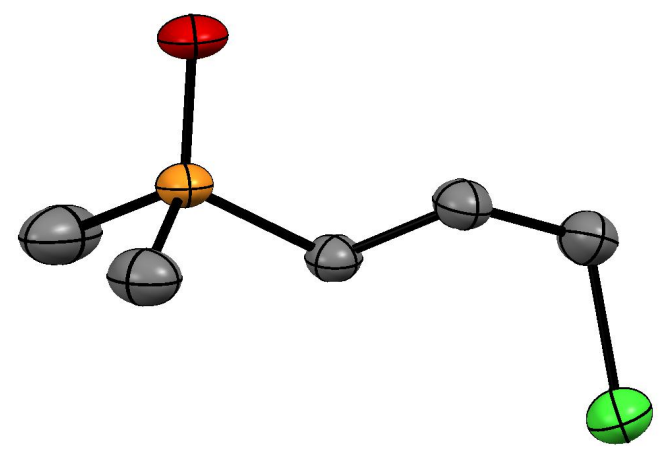

Figure 5. ORTEP drawing of 2 with thermal ellipsoids drawn at the 50\% level. The H-atoms are omitted for clarity.

2.2 Unsymmetrical bis(phosphine) oxides

Unsymmetrical bis(phosphine) oxides were synthesized according to the route in Scheme 5.

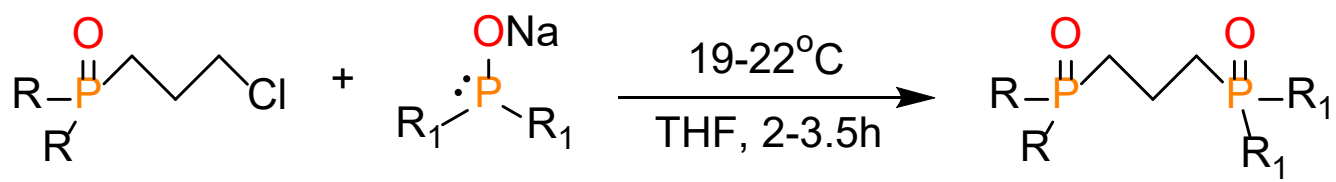

Scheme 5. Reaction of (3-chloropropyl)dialkylphosphine oxides with phosphinite anions to form unsymmetrical bis(phosphine) oxides.

Substitution of the chloride in (3-chloropropyl)dialkylphosphine oxides proceeded rapidly after addition to the phosphinite anion solutions. In most cases, the reactions were completed in under 30 minutes as indicated by ${ }^{31} \mathrm{P}$ NMR spectroscopy. The yields of the bis(phosphine) oxide products are shown in Table 2 . Note that the unsymmetrical bis(phosphine) oxides were synthesized in reasonable yields. The (3- 
chloropropyl)dimethylphosphine oxide starting material was used for all but one of the unsymmetrical oxides, but it should be apparent that any combination of R groups is likely possible on either end of the linker.

Table 2. Unsymmetrical Bis(phosphine) Oxides

\begin{tabular}{|c|c|c|c|}
\hline Product Number & Substrate & Product & Yield $(\%)^{\mathrm{a}}$ \\
\hline 8 & $\widehat{\mathrm{Cl}}$ & & $77 \%$ \\
\hline 9 & $\stackrel{\circ}{\mu} \leadsto \widehat{C l}_{\mathrm{Cl}}$ & & $74 \%$ \\
\hline 10 & $\stackrel{\circ}{\stackrel{\circ}{\mu}} \widehat{C}_{\mathrm{Cl}}$ & 1 & $67 \%$ \\
\hline 11 & $\widehat{\mathrm{Cl}}$ & & $69 \%$ \\
\hline 12 & & & $85 \%$ \\
\hline 13 & & & $24 \%$ \\
\hline
\end{tabular}

${ }^{\mathrm{a} A v e r a g e ~ o f ~ t w o ~ i s o l a t e d ~ y i e l d s ~}$

It is noted that as the solubility of the unsymmetrical bis(phosphine) oxides increases in organic solvents (i.e., as the polarity of the molecule decreases because the R groups get larger) the separation of the unsymmetrical molecules from impurities in the reaction solution becomes more difficult. (For example, compare the work-up for product 13 to those for products 8-12; see 
the Experimental section) Crystal structures of oxides $\mathbf{8}$ and $\mathbf{1 2}$ were obtained and are shown in Figure 6.
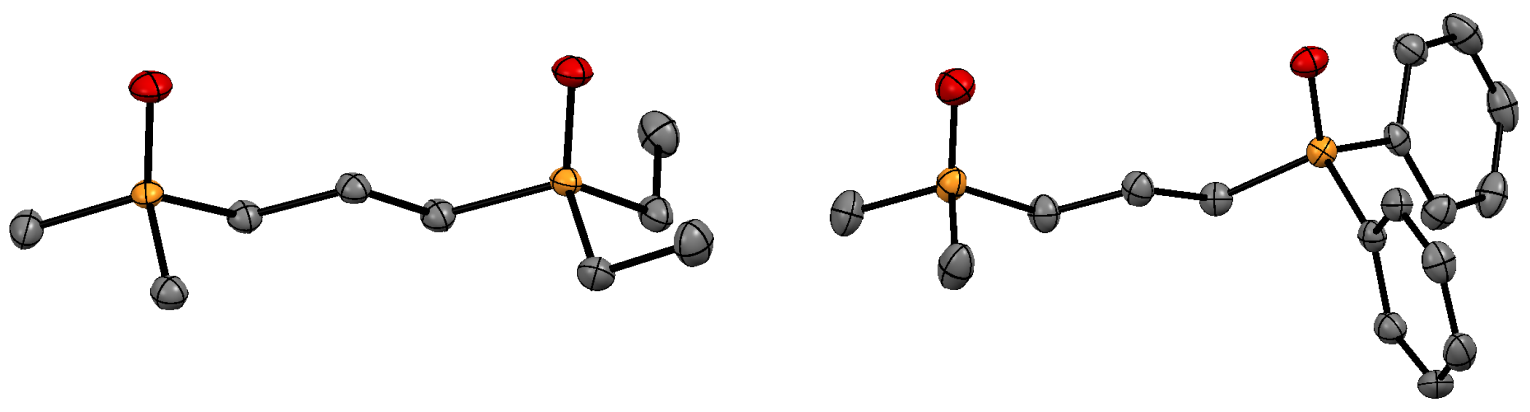

Figure 6. ORTEP drawings of molecules 8 and $\mathbf{1 2}$ with thermal ellipsoids drawn at the 50\% level. The H-atoms were omitted for clarity.

\subsection{Unsymmetric bidentate phosphines}

The unsymmetrical bis(phosphine) oxides were reduced to their corresponding unsymmetrical bidentate phosphines in mostly good yields following a reduction methodology [33] recently reported by our group, Scheme 6 . The phosphines and their yields are summarized in Table 3.

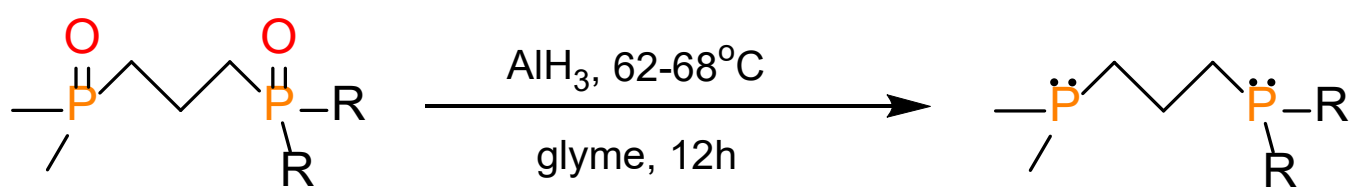

Scheme 6. Reduction of unsymmetrical bis(phosphine) oxides 
Table 3. Unsymmetrical bidentate phosphines

14

${ }^{\mathrm{a}}$ Average of two isolated yields. ${ }^{\mathrm{b}}$ Only reduction of the $\mathrm{PMe}_{2}$ unit occurred.

2.4 Complexes with unsymmetrical bidentate ligands

Several metal complexes were synthesized using the unsymmetrical bidentate ligands, Scheme 7. 

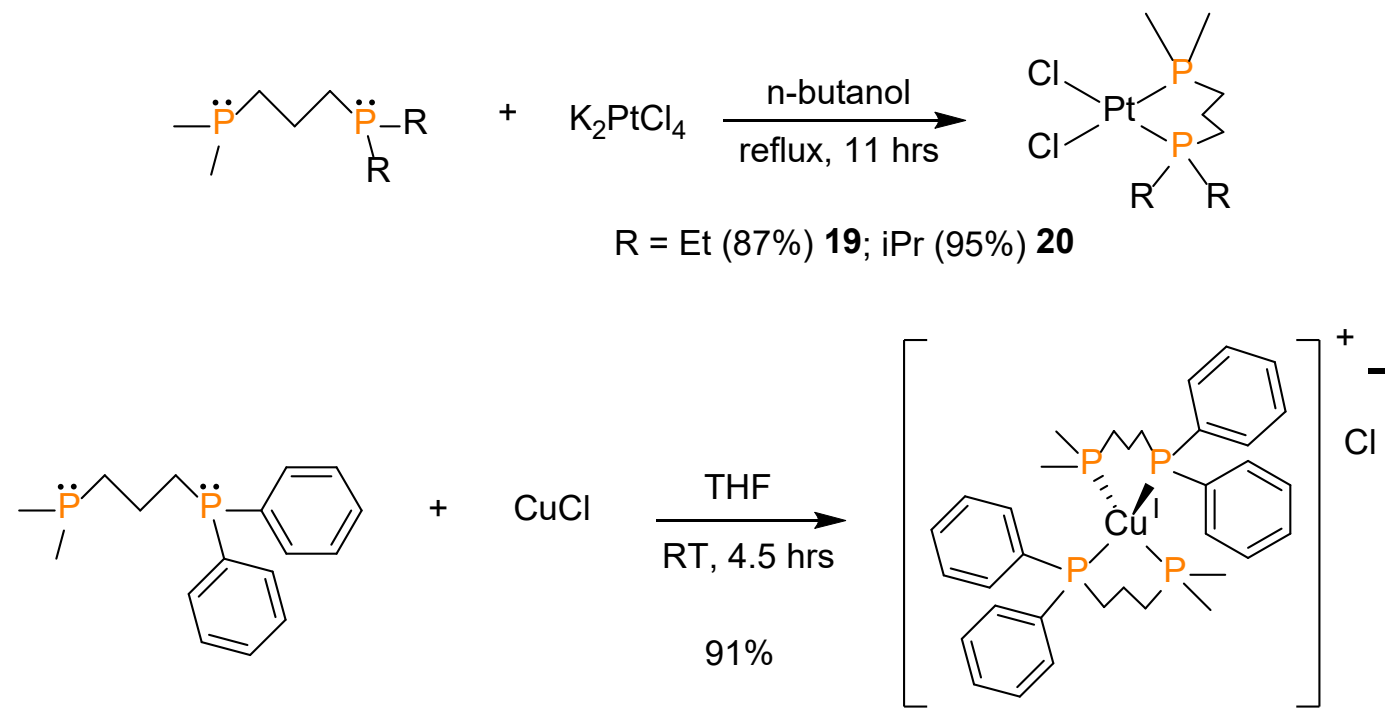

21

Scheme 7. Syntheses of cis- $\mathrm{Pt}\left((\mathrm{Me})_{2} \mathrm{P}\left(\mathrm{CH}_{2} \mathrm{CH}_{2} \mathrm{CH}_{2}\right) \mathrm{P}(\mathrm{iPr})_{2}\right)$ (top; 20) (the cis-

$\operatorname{Pt}\left((\mathrm{Me})_{2} \mathrm{P}\left(\mathrm{CH}_{2} \mathrm{CH}_{2} \mathrm{CH}_{2}\right) \mathrm{P}(\mathrm{Et})_{2}\right)$ derivative (19) was synthesized in the same manner) and $\left[\mathrm{Cu}^{\mathrm{I}}\left((\mathrm{Me})_{2} \mathrm{P}\left(\mathrm{CH}_{2} \mathrm{CH}_{2} \mathrm{CH}_{2}\right) \mathrm{P}(\mathrm{Ph})_{2}\right)\right] \mathrm{Cl}$ (below; 21). The crystal structures of these molecules are shown in Figure 7.
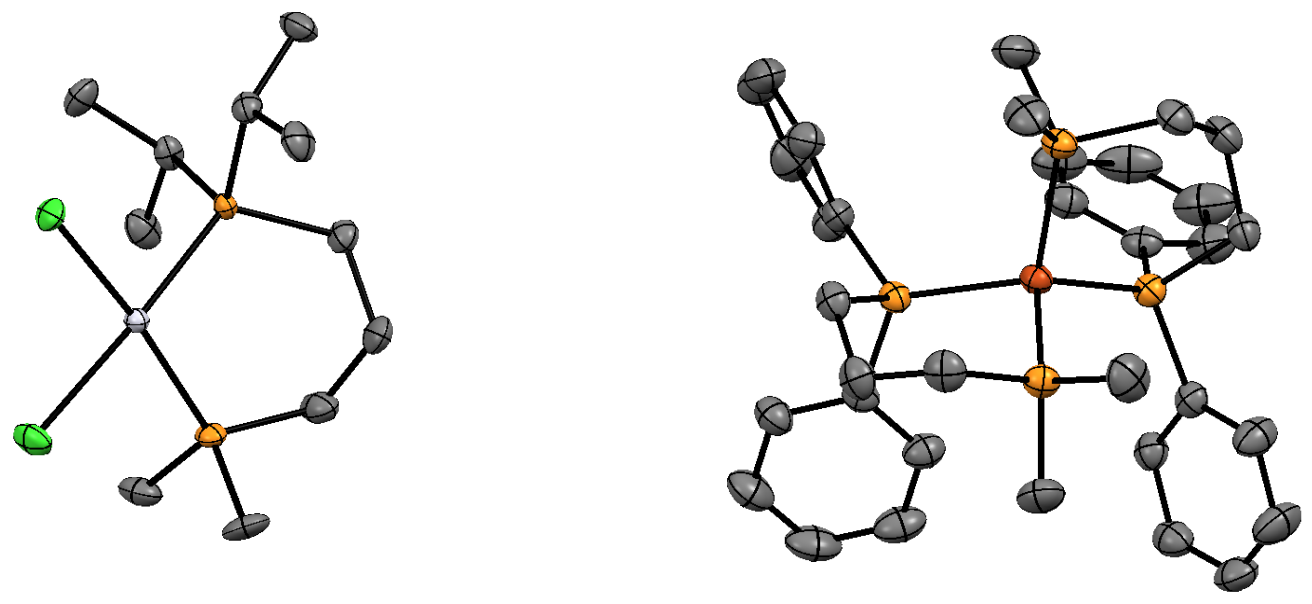
Figure 7. ORTEP drawings of cis- $\mathrm{Pt}\left((\mathrm{Me})_{2} \mathrm{P}\left(\mathrm{CH}_{2} \mathrm{CH}_{2} \mathrm{CH}_{2}\right) \mathrm{P}(\mathrm{iPr})_{2}\right) \mathrm{Cl}_{2}(\mathbf{2 0}$, left $)$ and the cationic portion of $\left[\mathrm{Cu}^{\mathrm{I}}\left((\mathrm{Me})_{2} \mathrm{P}\left(\mathrm{CH}_{2} \mathrm{CH}_{2} \mathrm{CH}_{2}\right) \mathrm{P}(\mathrm{Ph})_{2}\right)\right] \mathrm{Cl}$ (21, right) with thermal ellipsoids drawn at the $50 \%$ level. The H-atoms have been omitted for clarity.

It is interesting to note that the unsymmetrical phosphine ligands cause the copper atom to be an asymmetric center in the $\left[\mathrm{Cu}^{\mathrm{I}}\left((\mathrm{Me})_{2} \mathrm{P}\left(\mathrm{CH}_{2} \mathrm{CH}_{2} \mathrm{CH}_{2}\right) \mathrm{P}(\mathrm{Ph})_{2}\right)\right] \mathrm{Cl}$ complex (21). The crystal structure is centro-symmetric, which means the compound crystallized as a racemic mixture of two enantiomers.

Additional interesting results derived from the X-ray diffraction data are the bond angles and bond lengths of each complex. Diagrams of the bond angles are shown in Figure 8, and Table 4 shows the M-P bond lengths.
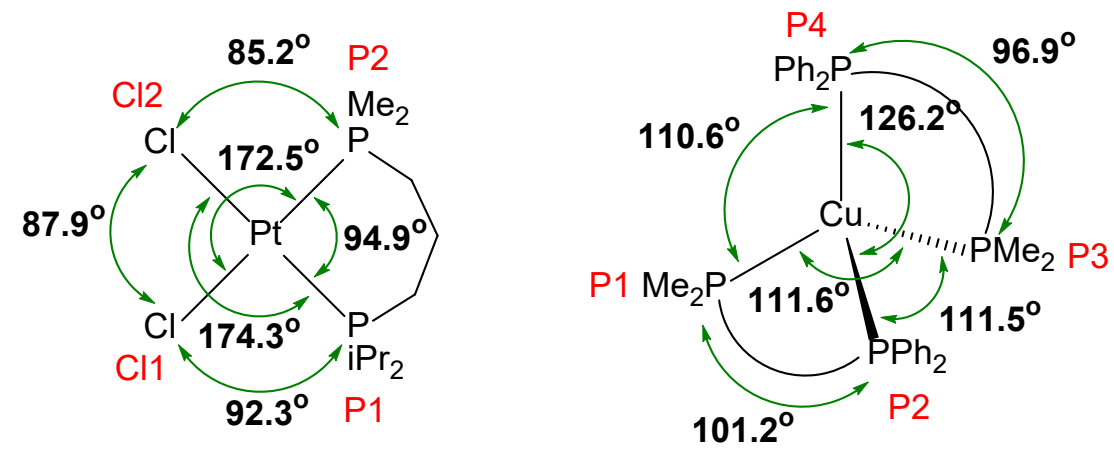

Figure 8. Diagrams of the bond angles in cis- $\mathrm{Pt}\left((\mathrm{Me})_{2} \mathrm{P}\left(\mathrm{CH}_{2} \mathrm{CH}_{2} \mathrm{CH}_{2}\right) \mathrm{P}(\mathrm{iPr})_{2}\right) \mathrm{Cl}_{2}$ (left; 20) and $\left[\mathrm{Cu}^{\mathrm{I}}\left((\mathrm{Me})_{2} \mathrm{P}\left(\mathrm{CH}_{2} \mathrm{CH}_{2} \mathrm{CH}_{2}\right) \mathrm{P}(\mathrm{Ph})_{2}\right)\right] \mathrm{Cl}$ (right; 21). 
Table 4. M-P and M-X bond lengths for the complexes with unsymmetrical ligands

\begin{tabular}{ccc}
\hline Complex & $\mathrm{M}-\mathrm{P}$ & $\mathrm{M}-\mathrm{X}$ \\
\hline${ }_{\text {cis }-\mathrm{Pt}\left((\mathrm{Me})_{2} \mathrm{P}\left(\mathrm{CH}_{2} \mathrm{CH}_{2} \mathrm{CH}_{2}\right) \mathrm{P}(\mathrm{iPr})_{2}\right) \mathrm{Cl}_{2}}$ & $2.243(2) \mathrm{P}_{1}$ & $2.361(2) \mathrm{Cl}_{1}$ \\
$(\mathbf{2 0})$ & $2.227(2) \mathrm{P}_{2}$ & $2.374(2) \mathrm{Cl}_{2}$ \\
\hline & $2.2740(9) \mathrm{P}_{1}$ & \\
{$\left[\mathrm{Cu}^{\mathrm{I}}\left((\mathrm{Me})_{2} \mathrm{P}\left(\mathrm{CH}_{2} \mathrm{CH}_{2} \mathrm{CH}_{2}\right) \mathrm{P}(\mathrm{Ph})_{2}\right)\right] \mathrm{Cl}$} & $2.249(1) \mathrm{P}_{2}$ & \\
$(\mathbf{2 1})$ & $2.264(1) \mathrm{P}_{3}$ & \\
& $2.2639(9) \mathrm{P}_{4}$ & \\
\hline
\end{tabular}

As one would expect, the unsymmetrical $(\mathrm{Me})_{2} \mathrm{P}\left(\mathrm{CH}_{2} \mathrm{CH}_{2} \mathrm{CH}_{2}\right) \mathrm{P}(\mathrm{iPr})_{2}$ ligand (15) causes the bond angles in Figure 8 and the bond lengths in Table 4 for $c i s-$ $\mathrm{Pt}\left((\mathrm{Me})_{2} \mathrm{P}\left(\mathrm{CH}_{2} \mathrm{CH}_{2} \mathrm{CH}_{2}\right) \mathrm{P}(\mathrm{iPr})_{2}\right) \mathrm{Cl}_{2}(\mathbf{2 0})$ to be different. Likewise, in the case of the tetrahedral copper center in $\left[\mathrm{Cu}^{\mathrm{I}}\left((\mathrm{Me})_{2} \mathrm{P}\left(\mathrm{CH}_{2} \mathrm{CH}_{2} \mathrm{CH}_{2}\right) \mathrm{P}(\mathrm{Ph})_{2}\right)\right] \mathrm{Cl}(\mathbf{2 1})$, all of the bond angles and bond lengths are different. However, it is odd that the bond angles and lengths are significantly different in the $\left[\mathrm{Cu}^{\mathrm{I}}\left((\mathrm{Me})_{2} \mathrm{P}\left(\mathrm{CH}_{2} \mathrm{CH}_{2} \mathrm{CH}_{2}\right) \mathrm{P}(\mathrm{Ph})_{2}\right)\right] \mathrm{Cl}$ complex (21) even though the two ligands are the same. These differences are due to the chirality of the complex, which requires that the four phosphorus atoms be structurally different. The lack of symmetry in the structures of the complexes demonstrates how different groups on the donor atoms at either end of a ligand can cause significant changes in the coordination environment of metal complexes.

\subsection{Brief investigation of reaction scope}

It was previously shown that the reaction of sodium dimethylphosphinite and 1,2dihaloalkanes resulted in complex mixtures of phosphorus products instead of clean conversion to the disubstituted or monosubstituted products (Scheme 8). 


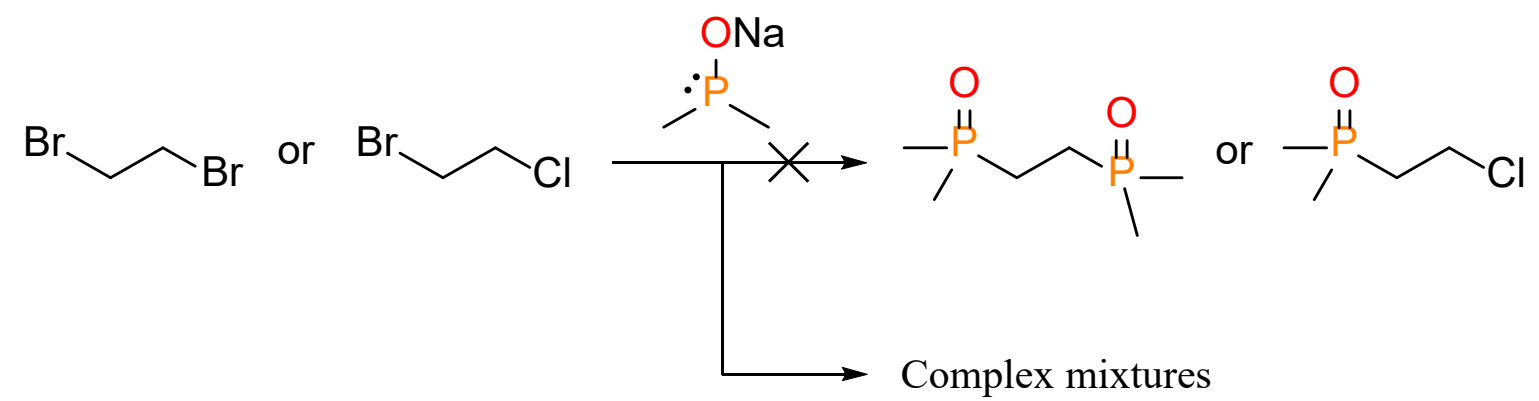

Scheme 8. Instead of the formation of the expected products, complex mixtures were found upon work-up.

This result prevented the synthesis of symmetric and unsymmetric bis(phosphine) oxides with ethene linkers using sodium phosphinites. In this work, synthesis of oxides with ethene linkers was attempted again with 1,2-dihaloalkanes. It was confirmed that the expected products were not formed in a significant quantity, but ${ }^{31} \mathrm{P}$ NMR spectra of the reaction mixtures showed the presence of tetramethylbis(phosphine) monoxide (22) as a major product, based on literature ${ }^{31} \mathrm{P}$ NMR chemical shifts and coupling constants [34]. The ${ }^{31} \mathrm{P}$ NMR spectrum of the crude material from the reaction of 1,2-dibromoethane and 2 equivalents of $\mathrm{NaOP}(\mathrm{Me})_{2}$ is shown in Figure 9. 


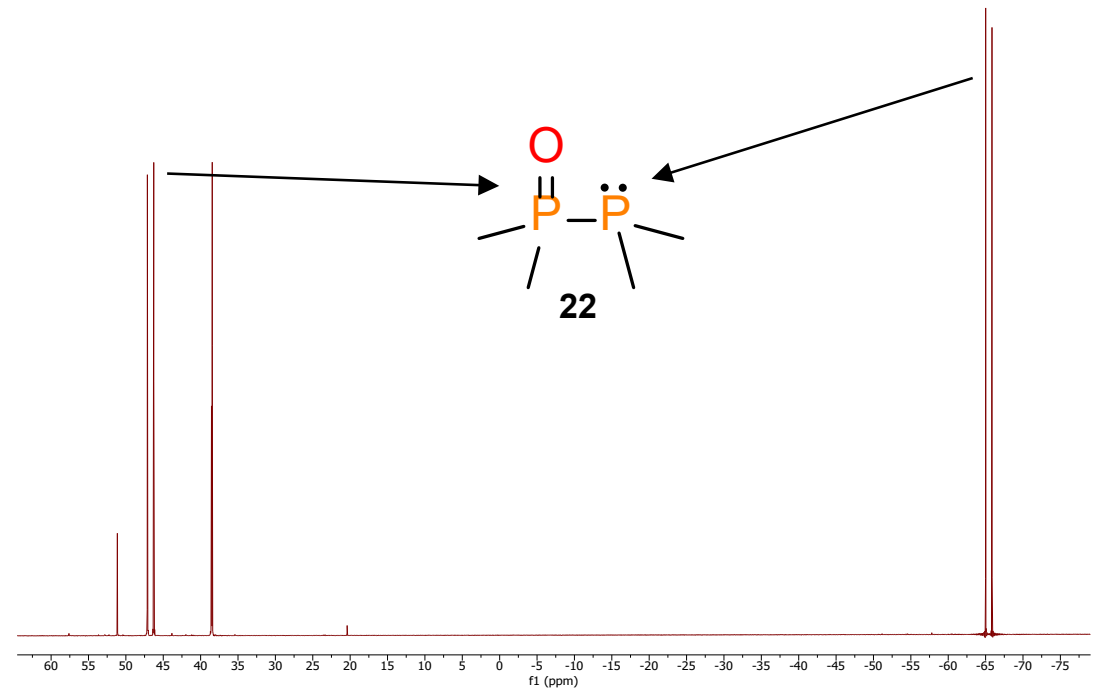

Figure 9. NMR of the crude material from the reaction of 1,2-dibromoethane with 2 equivalents of sodium dimethyl phosphinite. The reaction was quenched with 2-butanol and the solvent was removed under vacuum. The dry mixture was suspended in chloroform, filtered, and the solvent removed once again under vacuum.

This result explains why the reactions of $\mathrm{NaOP}(\mathrm{Me})_{2}$ with 1,2-dihaloalkanes form complex mixtures upon work-up, namely because the tetramethylbis(phosphine) monoxide decomposes to yield oxidation products upon work-up in air.

\section{Conclusions}

Six different unsymmetrical bis(phosphine) oxides $(\mathbf{8}-\mathbf{1 3})$ were synthesized by the route in Scheme 4. There are few previous reports of unsymmetrical bidentate phosphines, and their syntheses involve the use of malodorous and pyrophoric phosphine precursors. The key insight in the route to unsymmetrical phosphines reported here is the use of 1-bromo-3-chloropropane. The different rates of bromide and chloride substitution in this molecule allowed for the isolation 
of the (3-chloropropyl)dialkylphosphine oxide intermediates. Three examples of (3chloropropyl)dialkylphosphine oxides $(\mathbf{2}-\mathbf{4})$ were synthesized by reaction of sodium dialkylphosphinites with 1-bromo-3-chloropropane. Subsequent reaction of (3chloropropyl)dimethylphosphine oxide (2) or (3-chloropropyl)diisopropylphosphine oxide (4) with various sodium phosphinites yielded six different unsymmetrical bis(phosphine) oxides (Table 2). Reduction of four of the bis(phosphine) oxides bearing methyl groups on one of the phosphorus centers yielded the unsymmetrical bidentate phosphines, $(\mathrm{Me})_{2} \mathrm{P}\left(\mathrm{CH}_{2} \mathrm{CH}_{2} \mathrm{CH}_{2}\right) \mathrm{P}(\mathrm{R})_{2}$ (14 - 17) (Table 3). Two platinum dichloride bis(phosphine) complexes were also synthesized: cis- $\mathrm{Pt}\left((\mathrm{Me})_{2} \mathrm{P}\left(\mathrm{CH}_{2} \mathrm{CH}_{2} \mathrm{CH}_{2}\right) \mathrm{P}(\mathrm{Et})_{2}\right) \mathrm{Cl}_{2}$ (19) and cis- $\mathrm{Pt}\left((\mathrm{Me})_{2} \mathrm{P}\left(\mathrm{CH}_{2} \mathrm{CH}_{2} \mathrm{CH}_{2}\right) \mathrm{P}\left(\mathrm{Pr}_{2}\right) \mathrm{Cl}_{2}\right.$ (20); the X-ray crystal structure of cis- $\mathrm{Pt}\left((\mathrm{Me})_{2} \mathrm{P}\left(\mathrm{CH}_{2} \mathrm{CH}_{2} \mathrm{CH}_{2}\right) \mathrm{P}(\mathrm{iPr})_{2}\right) \mathrm{Cl}_{2}$ (20) was obtained. In addition, a racemic tetrahedral copper I complex was isolated, $\left[\mathrm{Cu}^{\mathrm{I}}\left((\mathrm{Me})_{2} \mathrm{P}\left(\mathrm{CH}_{2} \mathrm{CH}_{2} \mathrm{CH}_{2}\right) \mathrm{P}(\mathrm{Ph})_{2}\right)\right] \mathrm{Cl}$ (21), and its X-ray crystal structure obtained. A review of the literature reveals that uses for unsymmetrical bidentate phosphines are currently unexplored. But, the method or ligands described here may find use in tuning the electronics and sterics of transition metal catalysts by providing an alternative to symmetrical ligands. The synthetic method reported here is the first report of unsymmetrical bidentate phosphines being synthesized where the final step of the synthesis (the formation of the phosphine) is the only step forming an air-sensitive product. In attempts to make symmetrical and unsymmetrical 1,2-bis(phosphine) oxides via reactions of sodium phosphinites, it was observed that sodium dimethylphosphinite reacted with 1,2dibromoethane and 1-bromo-2-chloroethane to form tetramethyldiphosphine monoxide (22) among other products. This result implies that an unexpected reaction pathway is occurring other than just nucleophilic attack by the phosphorus or oxygen of the phosphinite. 


\section{Experimental}

\subsection{General Procedures and Instrumentation}

Unless otherwise stated, all reactions were done under an inert atmosphere of nitrogen in ovendried glassware. Standard Schlenk techniques were used for all reactions performed outside of a glovebox. Tetrahydrofuran (THF), diethyl ether, hexanes, and acetonitrile were dried using a DriSolv system employing $\mathrm{CuO}$ and molecular sieves. The THF, ether, hexanes, and acetonitrile were stored in a glovebox over activated molecular sieves prior to use. Anhydrous glyme was obtained from Acros Organics and stored over sieves in a glovebox. Additional solvents were dried by refluxing over sodium metal overnight, distilling, and then storing over sieves in a glovebox. Pentane was distilled immediately prior to its use in the extractions of the unsymmetrical bidentate phosphines in order to degas it. Diethyl phosphite was obtained from Sigma-Aldrich and distilled before use. 1-Bromo-3-chloropropane was obtained from the Eastman Chemical Company and distilled prior to use or used as received. Lithium aluminum hydride (LAH) was obtained as a pure white powder by removal of solvent from 1.0 M solutions obtained from Sigma-Aldrich or by washing solid gray LAH obtained from Sigma-Aldrich with diethyl ether, filtering the suspension, and removing the diethyl ether under vacuum. All other commercially obtained reagents and solvents were used without further purification unless specified. All synthesized organomagnesium reagents were titrated with salicylaldehyde phenylhydrazone according to the literature [35] and used immediately or stored overnight under

$\mathrm{N}_{2}$. Salicylaldehyde phenylhydrazone was prepared according to the literature [35]. Solutions of $2 \mathrm{M}$ sodium bis(trimethylsilyl)amide (NaHMDS) in THF were obtained from Acros Organics and titrated with 9-methyl-9H-fluorene in a modified literature method (see page 13) [36]. Thinlayer chromatography (TLC) was performed on either basic alumina plates for bis(phosphine) 
oxides or silica TLC plates for mono(phosphine) oxides and SPOs. The basic alumina plates were obtained from Macherey-Nagel. Silica gel $60 \mathrm{~F}_{254}$ plates were obtained from EM Scientific. TLC was visualized with ultraviolet light for aryl species or phosphomolybdic acid stains for alkyl phosphine oxides, which typically resolved as white spots upon heating. ${ }^{1} \mathrm{H}$ NMR spectra were collected on either a $500 \mathrm{MHz}$ Varian spectrometer or a $600 \mathrm{MHz}$ Bruker spectrometer and reported relative to deuterated solvent signals. ${ }^{1} \mathrm{H}$ NMR data is reported as follows: chemical shift $(\delta \mathrm{ppm})$, multiplicity, coupling constant $(\mathrm{Hz})$, and relative integration. ${ }^{13} \mathrm{C} \mathrm{NMR}$ spectra were collected on a $600 \mathrm{MHz}$ Bruker spectrometer $(151 \mathrm{MHz})$ and reported relative to tetramethyl silane. ${ }^{31} \mathrm{P}$ NMR data were collected on either a $500 \mathrm{MHz}$ Varian spectrometer or a $600 \mathrm{MHz}$ Bruker spectrometer (202 MHz or $243 \mathrm{MHz}$, respectively) and reported relative to $85 \% \mathrm{H}_{3} \mathrm{PO}_{4}$. High resolution mass spectrometry (HRMS) data were performed and analyzed by Dr. Felix Grun of the Mass Spectrometry Facility at the University of California Irvine $(\mathbf{2}, \mathbf{4}, \mathbf{8}-$ 18, 21) and Jeff Morré of the Mass Spectrometry Facility at Oregon State University $(\mathbf{1 9}, \mathbf{2 0})$. All samples were within acceptable error. Elemental analyses were done by Complete Analysis Laboratory in Highland Park, New Jersey $(\mathbf{3}, \mathbf{1 1}, \mathbf{1 3 - 2 1})$ and Atlantic Microlab in Norcross, Georgia $(4,8,9$, and 12$)$.

\subsection{General synthesis of (3-chloropropyl)dialkylphosphine oxides (2 - 4)}

A Schlenk flask was charged with an SPO (1 equivalent, ca. 1.3 M) and THF. To the phosphine oxide solution, a solution of NaHMDS (1 eq) was added dropwise at room temperature with stirring. After at least 15 minutes, the phosphinite anion suspension or solution was added slowly to a ca. 1.3 M solution of 1-bromo-3-chloropropane in THF (1.25 eq) in a Schlenk flask at room temperature. After 2-6 hours of stirring at room temperature the reaction was quenched with one 
volume equivalent of deionized water (equivalent volume to THF used to dissolve SPO) and extracted with one volume equivalent of dichloromethane (DCM) 5-10 times. (Check the explicit syntheses in the Electronic Supplementary Material for the specific number of extractions needed.) The combined organic extracts were dried over sodium sulfate and then filtered. The sodium sulfate was washed with dichloromethane and added to the filtrate. The solvent was removed in vacuo to yield a yellow oil. Purification of the crude (3chloropropyl)dialkylphosphine oxides was accomplished by either sublimation or a mixture of chromatography and distillation (see explicit syntheses).

\subsection{General synthesis of unsymmetrical tertiary bis(phosphine) oxides (8 - 13)}

A Schlenk flask was charged with a SPO (1 eq, ca. 0.2 M) and THF. To the phosphine oxide solution, a solution of NaHMDS (1 eq) was added dropwise at room temperature with stirring. After at least 15 minutes, a solution of a mixed alkyl chloride tertiary phosphine oxide (1 or $\mathbf{3})$ (ca. $0.2 \mathrm{M}$ ) in THF was added dropwise to the phosphinite anion solution/suspension maintained at room temperature. After 2-3.5 hours, the reaction was quenched with one or two volume equivalents of deionized water (depending on whether the aqueous or organic phase was collected) and extracted with either ethyl acetate or DCM (depending on which phase was collected, check explicit syntheses). Whichever phase was collected had its solvent removed in vacuo; organic extracts were dried before their solvent was removed in vacuo. The crude material thus obtained was dissolved in 5\% methanol/DCM and run through a short plug of basic alumina, which was washed with $50 \mathrm{~mL}$ of the methanol/DCM solution. After removal of solvent, the solids thus obtained were washed with cold ether, followed by dissolution and filtration through diatomaceous earth. Removal of solvent yielded a colorless solid (see explicit 
syntheses for more details; for 9 the workup and purification differs greatly from this general method).

\subsection{General synthesis of unsymmetrical bidentate phosphines (14 - 18)}

A ca. $1.0 \mathrm{M}$ solution of alane (6.4 equivalents) in glyme was prepared from aluminum trichloride $(0.2370 \mathrm{~g}, 1.78 \mathrm{mmol})$ and purified lithium aluminum hydride $(0.2026 \mathrm{~g}, 5.35 \mathrm{mmol}$; see the Electronic Supplementary Material for details). A Kjeldahl flask was charged with an unsymmetrical bis(phosphine) oxide (1 equivalent, $0.5 \mathrm{M}$ ) and glyme (most of the oxides were insoluble in glyme). A Kjeldahl flask was equipped with an addition funnel and charged with the ca. 1.0 M alane solution. The suspension of the oxide was maintained at room temperature and stirred while alane was added to the mixture dropwise. (The alane solubilizes the oxide and $\mathrm{H}_{2}$ begins forming.) The addition funnel was replaced with a reflux condenser and the reaction heated to $62-68^{\circ} \mathrm{C}$, whereupon a white precipitate formed. After 12 hours, gray solids had precipitated, and the reaction was cooled to room temperature and quenched by slow addition of a degassed solution of sodium phosphate (10 equivalents, $0.5 \mathrm{M})$ in deionized water. (The first few drops were added slowly while the mixture reacted violently with the water.) After 2 hours of stirring at room temperature, the mixture was extracted five times by syringe with $10 \mathrm{~mL}$ of freshly distilled pentane. The extracts were dried, cannula transferred to a new flask, and the solvent was removed in vacuo to yield a greasy oil. The oil was dissolved in a small amount of hexane and run through a short column of silica and eluted with diethyl ether. After removal of solvent, the oil was dissolved in diethyl ether and filtered through diatomaceous earth. Removal of the solvent yielded the pure phosphine oil. 


\subsection{X-ray structures}

Diffraction intensities for $\mathbf{2}, \mathbf{8}, \mathbf{1 2}, \mathbf{2 0}$, and 21 were collected at $173 \mathrm{~K}$ on a Bruker Apex2 CCD diffractometer using $\mathrm{CuK} \alpha$ radiation, $\lambda=1.54178 \AA$. Space groups were determined based on systematic absences $(\mathbf{2}, \mathbf{1 2}, \mathbf{2 0})$ and intensity statistics $(\mathbf{8}, \mathbf{2 1})$. Absorption corrections were applied by SADABS [37]. Structures were solved by direct methods and Fourier techniques and refined on $F^{2}$ using full matrix least-squares procedures. All non-H atoms were refined with anisotropic thermal parameters. H atoms in $\mathbf{8}$ and $\mathbf{1 2}$ were found from the residual density maps and refined without restrictions with isotropic thermal parameters. $\mathrm{H}$ atoms in $\mathbf{2 , 2 0}$ and 21 were refined in calculated positions in a rigid group model. The $-\mathrm{CH}_{2}-\mathrm{CH}_{2}-\mathrm{CH}_{2}$ - group in 2 and one of two solvent $\mathrm{CHCl}_{3}$ molecules in $\mathbf{2 1}$ are disordered over two positions in the ratio 1:1. The Flack parameter for $\mathbf{2 0}$ is $0.035(11)$. All calculations were performed by the Bruker SHELXL2014 package [38].

\section{Electronic Supplementary Material}

The crystallographic data for complexes $\mathbf{2 , 8}, \mathbf{1 2}, \mathbf{2 0}$, and 21 are deposited with the Cambridge Crystallographic Data Centre (CCDC 1936444, CCDC 1936443, CCDC 1936447, CCDC 1936445, CCDC 1936446, respectively). This data can be obtained free of charge at www.ccdc.ac.uk/datałrequest/cif. Specific syntheses of the molecules; additional references; and additional NMR spectra.

Acknowledgment Acknowledgment is made to the NSF (CHE-1503550) for the support of this research. The project described was supported, in part, by the Oregon State University Research Office. The content is solely the responsibility of the authors and does not necessarily represent 
the official views of the OSU Mass Spectrometry Center. The authors acknowledge the OSU Mass Spectrometry Center at Oregon State University and specific institutional instrument grants. Orbitrap Fusion Lumos -NIH \# 1S10OD020111-01, Waters Ion Mobility ToF Mass

Spectrometer - NIH \#1S10RR025628-01,Applied Biosystems 4000Qtrap- NIH \# 1S10RR022589-01,ABSciex Triple ToF 5600-NIH \#1S10RR027878-01. Dillon Bryant, Daniel Berg, and Alexi Overland are acknowledged for their contributions to this project.

\section{References}

1. W. Keim and R. P. Schulz, J. Mol. Catal. 92, 21 (1994).

2. K. Nozaki, N. Sato, Y. Tonomura, M. Yasutomi, H. Takaya, T. Hiyama, T. Matsubara, and N. Koga, J. Am. Chem. Soc. 119, 12779 (1997).

3. O. Daugulis and M. Brookhart, Organometallics 21, 5926 (2002).

4. R. Drozdzak, B. Allaert, N. Ledoux, I. Dragutan, V. Dragutan, and F. Verpoort, Coord. Chem. Rev. 249, 3055 (2005).

5. V. Percec, G. M. Golding, J. Smidrkal, and O. Weichold, J. Org. Chem. 69, 3447 (2004).

6. J. P. Wolfe and S. L. Buchwald, J. Am. Chem. Soc. 119, 6054 (1997).

7. T. P. Dang and H. B. Kagan, J. Chem. Soc. Chem. Commun. 481 (1971).

8. A. Miyashita, A. Yasuda, H. Takaya, K. Toriumi, T. Ito, T. Souchi, and R. Noyori, J. Am. Chem. Soc. 102, 7932 (1980).

9. M. J. Burk, J. Am. Chem. Soc. 113, 8518 (1991).

10. C. A. Tolman, Chem. Rev. 77, 313 (1977).

11. R. Atkins, G. Brewer, E. Kokot, G. M. Mockler, and E. Sinn, Inorg. Chem. 24, 127 (1985). 
12. K. M. Omberg, G. D. Smith, D. A. Kavaliunas, P. Chen, J. A. Treadway, J. R. Schoonover, R. A. Palmer, and T. J. Meyer, Inorg. Chem. 38, 951 (1999).

13. J. G. Gilbert, A. W. Addison, A. Y. Nazarenko, and R. J. Butcher, Inorganica Chim. Acta 324, 123 (2001).

14. V. V. Grushin, Chem. Rev. 104, 1629 (2004).

15. H. Fernández-Pérez, P. Etayo, A. Panossian, and A. Vidal-Ferran, Chem. Rev. 111, 2119 (2011).

16. K. Vehlow, S. Maechling, and S. Blechert, Organometallics 25, 25 (2006).

17. L. D. Brown, S. Datta, J. K. Kouba, L. K. Smith, and S. S. Wreford, Inorg. Chem. 17, 729 (1978).

18. R. B. King and J. C. Cloyd, J. Am. Chem. Soc. 97, 53 (1975).

19. R. B. King and P. N. Kapoor, Inorg. Chem. 11, 1524 (1972).

20. S. O. Grim and R. C. Barth, J. Organomet. Chem. 94, 327 (1975).

21. F. R. Benn, J. C. Briggs, and C. A. McAuliffe, J. Chem. Soc. Dalton Trans. 293 (1984).

22. J. C. Briggs, C. A. McAuliffe, W. E. Hill, D. M. A. Minahan, and G. Dyer, J. Chem. Soc. Perkin Trans. 2321 (1982).

23. D. Rehder, F. Süßmilch, W. Priebsch, and M. Fornalczyk, J. Organomet. Chem. 411, 357 (1991).

24. L. Manojlović-Muir, D. Millington, K. W. Muir, D. W. A. Sharp, W. E. Hill, J. V.

Quagliano, and L. M. Vallarino, J Chem Soc Chem Commun 999 (1974).

25. K. Inoguchi, S. Sakuraba, and K. Achiwa, Synlett 1992, 169 (1992).

26. M. Diéguez, O. Pàmies, A. Ruiz, Y. Díaz, S. Castillón, and C. Claver, Coord. Chem. Rev. 248, 2165 (2004). 
27. A. Pfaltz and W. J. Drury, Proc. Natl. Acad. Sci. 101, 5723 (2004).

28. N. Yoshinari, A. Kakuya, R. Lee, and T. Konno, Bull. Chem. Soc. Jpn. 88, 59 (2015).

29. R. J. Puddephatt, Coord. Chem. Rev. 216-217, 313 (2001).

30. M. J. Irwin, J. J. Vittal, G. P. A. Yap, and R. J. Puddephatt, J. Am. Chem. Soc. 118, 13101 (1996).

31. A. J. Kendall, C. A. Salazar, P. F. Martino, and D. R. Tyler, Organometallics 33, 6171 (2014).

32. A. J. Kendall, D. T. Seidenkranz, and D. R. Tyler, Organometallics 36, 2412 (2017).

33. N. I. Rinehart, A. J. Kendall, and D. R. Tyler, Organometallics 37, 182 (2018).

34. M. Volkholz, O. Stelzer, and R. Schmutzler, Chem. Ber. 111, 890 (1978).

35. B. E. Love and E. G. Jones, J. Org. Chem. 64, 3755 (1999).

36. M. E. Bowen, B. R. Aavula, and E. A. Mash, J. Org. Chem. 67, 9087 (2002).

37. G. Sheldrick, (1998).

38. G. M. Sheldrick, Acta Crystallogr. Sect. C Struct. Chem. 71, 3 (2015). 